\title{
O REGIME DE PROTEÇÃO AOS MIGRANTES, REFUGIADOS E SOLICITANTES DE REFÚGIO DO PACTO INTERNACIONAL DE DIREITOS ECONÔMICOS, SOCIAIS E CULTURAIS DAS NAÇÕES UNIDAS
}

\author{
The United Nations International Covenant on Economic, \\ Social and Cultural Rights protection regime \\ for migrants, refugees and asylum seekers
}

Renato Zerbini Ribeiro Leão*

\begin{abstract}
Resumo. Por meio de uma análise das principais produções do Comitê de Direitos Econômicos, Sociais e Culturais das Nações Unidas (CDESC), esse artigo intenta demonstrar o sólido regime de proteção aos migrantes, refugiados e solicitantes de refúgio emergido do Pacto Internacional de Direitos Econômicos, Sociais e Culturais (PIDESC). A metodologia consistiu de revisão documental, acrescida da participação individual ativa do autor no diálogo construtivo com os Estados partes do PIDESC, no desenvolvimento, elaboração, conclusão e aprovação oficial dessa produção, consubstanciada em documentos oficiais do CDESC na matéria.
\end{abstract}

Palavras-chave: migrantes; refugiados; solicitantes de refúgio; proteção; Pacto Internacional de Direitos Econômicos, Sociais e Culturais.

\begin{abstract}
This article presents an analysis of the United Nations Committe on EConomic, Social and Cultural Rights (CESCR) main production, seeking to demonstrate the solid regime of protection for migrants, refugees and asylum seekers emerging from the International Covenant on Economic, Social and Cultural Rights (ICESCR). The methodology consisted of document review plus the author's active individual participation in constructive dialogue with ICESCR States Parties, in the development, drafting, conclusion and official approval of this production embodied in official CESCR documents.
\end{abstract}

Keywords: migrants; refugees; asylum seekers; protection; International Covenant on Economic, Social and Cultural Rights.

\footnotetext{
Membro e atual Presidente do Comitê de Direitos Econômicos, Sociais e Culturais da ONU; Professor Titular da FAJS/UniCEUB e do Mestrado em Ciência Política do UniEURO em Brasília. Brasília - DF, Brasil. E-mail: rzrleao@uol.com.br. Orcid: 0000-0002-0896-3624.
} 


\section{Introdução}

Um regime é um conjunto de instituições, de normas, de princípios e de regras capazes de influenciar, gerando-lhes um padrão de conduta, os Estados, as organizações internacionais e os indivíduos em uma determinada agenda ou tema (Krasner, 1982, p. 186).

O Pacto Internacional de Direitos Econômicos, Sociais e Culturais (PIDESC) apresenta um regime consolidado de proteção aos migrantes, refugiados e solicitantes de refúgio. Este consta de instituições (Comitê de Direitos Econômicos, Sociais e Culturais das Nações Unidas - CDESC), de normas (Carta da ONU; Declaração Universal de Direitos Humanos e o PIDESC), princípios (igualdade e não discriminação, união familiar e pro homine), de documentos (observações gerais, declarações e cartas do CDESC) e de regras (Pacto da Sunt Servanda; regra da norma mais favorável e regra do esgotamento dos recursos internos) que consagram a existência de um verdadeiro regime de proteção aos migrantes e refugiados oriundo do PIDESC.

A importância desse artigo é identificar e reconhecer este regime, pouco conhecido pelo público em geral, mas que em matéria de preocupações e de recomendações para a afirmação de direitos e o desenvolvimento de políticas públicas na seara do trabalho, saúde, educação, moradia, transporte, cultura e ciência para os migrantes, refugiados e solicitantes de refúgio é o mais robusto da proteção internacional dos direitos humanos.

Trata-se de um regime capaz de recordar aos Estados partes do PIDESC ${ }^{1}$ quais são os direitos econômicos, sociais e culturais que as pessoas fugitivas de conflitos armados; de perseguições por seus países de origem em razão de raça, religião, grupo social, nacionalidade, opinião política ou ideologia devem ter minimamente assegurados. Segundo o Alto Comissariado das Nações Unidas para os Refugiados (ACNUR), em 2018 são mais de 70,8 milhões de pessoas nestes contextos. É o maior número já registrado nas quase sete décadas de existência dessa agência da ONU. Em 2018, diariamente, 37 mil pessoas tiveram que abandonar o lugar onde residiam em busca de segurança (ACNUR, 2019, p. 1) ${ }^{2}$. O regime do PIDESC abarca também aquelas pessoas que simplesmente desejam melhorar suas condições de vida. Esse raciocínio aplica-se tanto para os países de destino final, como para os países de trânsito dessas pessoas. Neste regime, os próprios migrantes, refugiados já reconhecidos e solicitantes de refúgio, estando estes na jurisdição de um dos Estados partes do PIDESC e de seu protocolo facultativo, podem reclamar diretamente a violação de um de seus direitos econômicos, sociais e culturais.

1 Em 10 de agosto de 2019 são 170 os Estados partes do PIDESC.

2 Ademais, esse número representa um aumento de 2,3 milhões na comparação com 2017 e se aproxima das populações de países como Tailândia e Turquia. O contingente também equivale ao dobro dos deslocados forçados registrados 20 anos atrás. 
Para o CDESC, órgão de interpretação, supervisão e monitoramento do PIDESC, todos os migrantes, os refugiados já reconhecidos e os solicitantes de refúgio, ainda que os tratamentos a eles dispensados sejam guiados por marcos jurídicos diferentes, têm os mesmos direitos humanos universais e liberdades fundamentais ${ }^{3}$. Isso porque todas as pessoas na jurisdição de um Estado parte do PIDESC podem desfrutar dos direitos nele reconhecidos. Essa lógica jurídica inclui aos solicitantes de refúgio, aos refugiados e outros migrantes ${ }^{4}$.

Em prol da identificação e do reconhecimento desse regime, esse artigo estrutura-se a partir das características centrais do PIDESC e do CDESC. Em seguida, apresenta as principais produções do Comitê: as observações gerais; as declarações e cartas abertas; assim como as observações conclusivas, ilustradas à luz da temática migratória, dos refugiados e solicitantes de refúgio. Finalmente, discorre sobre o Protocolo Facultativo ao PIDESC, tratado internacional que permite à cidadania de seus Estados partes a individualmente denunciá-los por supostas violações aos artigos do PIDESC.

\section{O Pacto Internacional de Direitos Econômicos, Sociais e Culturais (PIDESC)}

O PIDESC é um tratado internacional multilateral do sistema de direitos humanos da ONU. Trata-se de um dos pilares essenciais da Carta Internacional de Direitos Humanos: um conjunto de convenções internacionais que ademais do PIDESC alberga o Pacto Internacional de Direitos Civis e Políticos (PIDCP) e a Declaração Universal de Direitos Humanos (DUDH) de 10 de dezembro de 1948. O PIDESC e o PIDCP foram adotados pela Assembleia Geral das Nações Unidas em 16 de dezembro de 1966 (Resolução 2200 A XXI), entrando em vigência em $1976^{5}$.

O PIDESC identifica três responsabilidades que recaem sobre os Estados para a proteção dos direitos neles contidos: a de respeitar, isto é, os Estados devem abster-se de interferir direta ou indiretamente nesses direitos; a de proteger, vale dizer, os Estados devem tomar medidas para assegurar que outros, como os empresários, grupos políticos ou qualquer pessoa possa interferir nesses direitos; e, a de desfrutar, ou seja, os Estados devem tomar medidas para a realização desses direitos.

3 Decisão em consonância com a Declaração de Nova Iorque para os Refugiados e os Migrantes, aprovada em 19/09/2016 pela Assembleia Geral da ONU.

4 O CDESC considera que no caso dos refugiados a Convenção sobre o Estatuto dos Refugiados de 1951 das Nações Unidas e seu Protocolo de 1967 ditam uma série de disposições relativas aos direitos econômicos, sociais e culturais dos refugiados. Na prática, entretanto, essas disposições concedem aos Estados uma ampla margem de apreciação. Por isso, o PIDESC deve ser considerado complementar à Convenção.

5 O PIDESC e o PIDCP entraram em vigência em 3 de janeiro e 23 de março, respectivamente, após conseguirem as ratificações necessárias. 
As normas do PIDESC dispõem sobre igualdade de direitos entre homens e mulheres, direito ao trabalho, direito a condições equitativas e satisfatórias de trabalho, direito a fundar e se afiliar a sindicatos, direito à seguridade social, direito à proteção e a assistência à família, direito a um nível de vida adequado, direito ao mais alto nível possível de saúde física e mental, direito à educação, e, direito à cultura e ao gozo dos benefícios do progresso científico. Estes, à luz dos princípios da livre determinação, da igualdade e da não discriminação.

O primeiro parágrafo do artigo segundo do PIDESC exige que os Estados partes adotem medidas imediatas para garantir a todas as pessoas em suas jurisdições o pleno exercício dos direitos nele garantidos. Tais medidas deverão ser próprias ou alcançadas mediante a assistência e a cooperação internacionais. A Carta de San Francisco ou Carta da ONU (a partir da literalidade de seus artigos 1.3 e 55, incisos "a" e "c", lidos conjuntamente com o artigo 56) consagra a interpretação extensiva de que a proteção internacional aos direitos humanos deve ser considerada como uma questão vinculada aos interesses da comunidade internacional. Portanto, em prol da afirmação da dignidade humana, a cooperação internacional constituirá uma fonte de restrições à discricionariedade estatal. A restrição a qualquer um dos atuais patamares da proteção internacional dos direitos humanos, inclusive os emanados pelo CDESC, poderia ser interpretada como uma violação a princípios basilares da proteção internacional da pessoa humana, como o princípio da não redução de parâmetros da proteção dos direitos humanos, o princípio da norma mais favorável e o princípio pro homine (Leão, 2010, p. 73-74). Esse entendimento guia os membros do CDESC na aplicação e interpretação do PIDESC também nos assuntos relacionados aos migrantes, refugiados e solicitantes de refúgio.

O artigo 2.1 do PIDESC versa sobre a realização progressiva dos direitos. A própria expressão "se compromete a adotar medidas, por todos os meios apropriados, incluindo a adoção de medidas legislativas" exige que todos os Estados partes comecem a adotar medidas imediatas a fim de conseguir para todos o gozo pleno dos direitos contidos no Pacto (CDESC, 2008, par. 7, p. 18). Estas incluem, não esgotando outras possibilidades, as de caráter administrativo, financeiro, educacional e social. Em consequência, os Estados partes obrigam-se juridicamente a adotar medidas legislativas, particularmente, quando as leis existentes sejam claramente incompatíveis com as obrigações contraídas em virtude do PIDESC (ONU, 1996, p. 10).

Já a expressão "assegurar progressivamente o pleno exercício dos direitos" obriga aos Estados partes, independentemente de seu grau de desenvolvimento ou riqueza nacional, a avançar imediatamente e à brevidade possível para a efetividade dos DESC (ONU, 1996, p. 10). Particularmente, no que toca as disposições não discriminatórias e a obrigação dos Estados partes em se absterem de violar, por ação ou omissão, as medidas protetoras legais ou de 
outros tipos que exigem cumprimento imediato. Inclusive, o CDESC afirmou que essa obrigação existe independentemente à produção de um aumento nos recursos disponíveis. Todos os recursos existentes devem dedicar-se a tornar efetivos os direitos proclamados pelo PIDESC da maneira mais eficiente possível (ONU, 2008, par. 7-10, p. 11).

O CDESC identificou como obrigações de efeito imediato a adoção de medidas para a efetivação plena dos direitos reconhecidos no PIDESC e a proibição da discriminação. Suas existências ou não oferecem pilares para avaliar supostas violações do Estado, seja por ação ou omissão. Os DESC não são puramente programáticos. Pelo contrário impõe obrigações operativas diretas. O não cumprimento destas pode ser justiciável. Por exemplo, a existência de leis ou de práticas estatais que discriminem por razões como gênero, raça, discapacidade, orientação sexual ou nacionalidade, dentre outras, impondo barreiras ao desfrute dos DESC, constituem violações às obrigações de efeito imediato. Também, a falta de políticas públicas para a realização dos direitos ou a demora em derrogar legislação ou práticas discriminatórias constituem violações desse tipo (ONU, ECOSOC, Doc. E/C.12/GC/20, 2009, par. 30, p. 10).

De fato, o CDESC, em sua Observação Geral no 1 , assinalou que o PIDESC atribui especial importância ao conceito de realização progressiva dos DESC. Com efeito, os Estados partes foram instados a incluírem em seus relatórios dados capazes de avaliar o progresso alcançado quanto à aplicação efetiva desses direitos dentro de prazos adequados. Essa efetividade progressiva demanda uma reflexão acerca das dificuldades no mundo real quanto à efetividade dos DESC à luz das obrigações estatais de alcançarem esses objetivos o mais eficaz e expedito possível. Todas as medidas deliberadamente retroativas deverão ser consideradas de maneira cautelosa, sendo plenamente justificadas apenas quando se referirem ao máximo dos recursos disponíveis (ONU, 2008 , par. 7-10, p. 11). Isto não significa que os Estados partes possam delongar indefinidamente a adoção de medidas capazes de garantir os direitos das pessoas sujeitas a sua jurisdição. Pelo contrário, o PIDESC impõe uma série de medidas de efeito imediato, aplicáveis inclusive em benefício de um grupo numeroso de migrantes, refugiados e solicitantes de refúgio que de súbito adentram-se às jurisdições desses Estados.

O artigo 2.2 do PIDESC obriga aos Estados partes a se absterem de comportamentos discriminatórios, modificando leis e práticas que permitam a discriminação. Proíbe os particulares e os organismos públicos a realizar práticas discriminatórias. Em casos de discriminação, procedimentos judiciais e outros métodos de recursos devem ser garantidos. Esse artigo pontifica que a origem nacional das pessoas é um motivo explícito de não discriminação. E isto, sem nenhuma dúvida, inclui aos migrantes, aos refugiados e aos solicitantes de refúgio. Inclusive estando estes em situação de irregularidade 
como, por exemplo, não documentados ou portando documentos falsos (ONU, 2004, p. 15).

Os Estados partes no PIDESC contam com certa margem de apreciação à hora de decidirem quais medidas adotarem na efetivação progressiva dos direitos enunciados no Pacto. Estas devem ser deliberadas, concretas e claramente orientadas para a satisfação das obrigações nele reconhecidas. Senão ainda, toda distinção, exclusão, restrição, preferência ou outro trato diferente por motivos de nacionalidade ou condição jurídica deve ajustar-se à lei, perseguir um fim legítimo e ser sempre proporcional ao objetivo buscado. O CDESC estabeleceu que a proteção contra a discriminação não pode estar condicionada à regularidade de uma pessoa no país de acolhida. Em sua Observação Geral no 20 o Comitê sublinhou que não se deve impedir o acesso aos direitos do Pacto por razões de nacionalidade. Por essa razão, todas as crianças em um Estado parte, inclusive as indocumentadas, têm direito a receber uma educação, uma alimentação adequada e uma atenção de saúde assequíveis (ONU, ECOSOC, Doc. E/C.12/GC/20, 2009, par. 30, p. 10).

Para o CDESC a saúde é um direito humano fundamental e indispensável para o exercício dos demais direitos humanos. Todo ser humano tem direito ao desfrute do mais alto nível possível de saúde capaz de lhe permitir viver dignamente segundo o artigo 12 do PIDESC. Em sua Observação Geral no 14, que trata do direito ao desfrute do nível mais alto possível de saúde, o Comitê alertou que os Estados têm a obrigação de respeitar o direito à saúde, particularmente abstendo-se de denegar ou limitar o igual acesso de todas as pessoas, incluídos, os solicitantes de asilo e os imigrantes ilegais, aos serviços de saúde preventivos, curativos e paliativos; não impondo práticas discriminatórias como políticas de Estado; senão ainda recusando-se a impor práticas discriminatórias quanto à saúde e às necessidades da mulher, aí incorporadas as migrantes, as refugiadas e as solicitantes de refúgio (ONU, ECOSOC, Doc. E/C.12/2000/4, 2000, par. 34, p. 13).

\section{O Comitê de Direitos, Econômicos, Sociais e Culturais (CDESC)}

O CDESC é um órgão internacional do sistema ONU que está conformado por 18 especialistas independentes. Ele aplica, interpreta e monitora o PIDESC. Foi estabelecido pela resolução 1985/17 do Conselho Econômico e Social da ONU (ECOSOC) em 28 de maio de 1985.

Todos os Estados partes no PIDESC estão obrigados a submeter relatórios ao CDESC sobre a implementação e aplicação dos direitos dispostos no Pacto. O primeiro relatório deve ser enviado ao cabo dos dois primeiros anos da vigência do PIDESC. Depois, a cada cinco anos deverão encaminhar seus relatórios de seguimento àquele relatório inicial. O CDESC examinará cada 
relatório e endereçará suas preocupações e recomendações aos Estados partes na forma de observações conclusivas.

O CDESC reúne-se em Genebra, em períodos de sessões anuais. O Comitê adota sua interpretação das disposições do PIDESC em forma de observações gerais. Também emite cartas e declarações sobre os mais variados assuntos para a afirmação dos DESC na seara internacional.

\section{A migração nas observações gerais do CDESC}

Até julho de 2019, o CDESC adotou 24 observações gerais. Estas auxiliam os Estados partes e a comunidade em geral a entenderem o alcance e o significado de cada um dos artigos do PIDESC. Orientam os Estados, os tribunais judiciais, as distintas instâncias administrativas e o público em geral acerca dos direitos humanos, dos direitos fundamentais e das liberdades que todo ser humano pode desfrutar à luz do Pacto. Em seu processo de consubstanciação, as observações gerais contam com um relator ou correlatores, apoio da secretaria técnica do Alto Comissariado das Nações Unidas para os Direitos Humanos (ACNUDH), diálogos com outras agências do sistema ONU, audiências públicas com parceiros da sociedade civil e entidades interessadas, debates com universidades e fundações afins à temática específica. Sua última versão rascunhada fica à disposição do público geral na página eletrônica do CDESC por um prazo razoável a fim de receber comentários e sugestões pertinentes antes da aprovação, pelo Comitê, de sua versão final.

A temática migratória desfila destacadamente em várias das observações gerais do CDESC. Na observação Geral no 18 que trata acerca do direito ao trabalho, o Comitê sublinhou que o princípio da não discriminação, segundo o estipulado no parágrafo 2 do artigo 2 do PIDESC e no artigo 7 da Convenção Internacional sobre a Proteção dos Direitos de Todos os Trabalhadores Migrantes e de seus Familiares, deve ser aplicado às oportunidades de emprego de trabalhadores migrantes e de suas famílias. A esse respeito o Comitê destacou a necessidade de planos nacionais de ação desenhados para respeitar e promover tal princípio mediante medidas adequadas, tanto legislativas como de outro tipo (ONU, ECOSOC, Doc. E/C.12/GC/18, 2005, par. 18, p. 7). O Comitê preocupa-se em conectar suas análises e fundamentos com outros tratados internacionais do sistema de tratados de direitos humanos das Nações Unidas. Trata-se da materialização da ideia de sinergia do sistema ONU em prol da afirmação da dignidade humana e dos direitos humanos de categorias ou grupos específicos como os migrantes, refugiados, solicitantes de refúgio e deslocados internos.

Em sua Observação Geral n 19, o Comitê interpretou o artigo 9 do PIDESC acerca do direito de toda pessoa à seguridade social, inclusive ao 
seguro social. Na visão do CDESC, tal direito, em consequência de seu caráter redistributivo, desempenha um papel importante para reduzir e mitigar a pobreza, prevenir a exclusão social e promover a inclusão social. Esse direito inclui o de obter e manter prestações sociais, sem discriminação, com a finalidade de obter proteção, particularmente contra a falta de ingressos procedentes do trabalho devido a doenças, invalidez, maternidade, acidentes laborais, velhice ou morte de um familiar; os gastos excessivos de atenção de saúde; e, o apoio familiar insuficiente, particularmente para os filhos e outros familiares dependentes (ONU, ECOSOC, Doc. E/C.12/GC/19, 2007, par. 2, p. 2). Uma inteligência que guarda absoluta conexão com a vulnerabilidade extrema dos refugiados e solicitantes de refúgio. Ademais, tal interpretação está em convergência com o direito internacional dos refugiados no que toca à aplicação do princípio da união familiar. Para os imigrantes e refugiados, a união familiar é um princípio de vital importância de cara a um exitoso processo de integração no país de acolhida. Para tanto, os Estados partes no PIDESC devem realizar todos os esforços necessários em termos de legislações e políticas públicas em prol dos imigrantes e refugiados.

O CDESC preocupa-se com essa questão, pois ele diz textualmente que na seara da acessibilidade as prestações devem ser concedidas oportunamente e os beneficiários devem ter acesso físico aos serviços de seguridade social com a finalidade de obter as prestações, informações e fazer as cotizações quando corresponda. Os trabalhadores migrantes devem ter os meios resguardados pelos Estados partes no PIDESC para esse acesso físico às prestações da seguridade social (ONU, ECOSOC, Doc. E/C.12/GC/19, 2007, par. 27, p. 9).

Os deslocados internos não devem sofrer nenhum tipo de discriminação no gozo de seu direito à seguridade social, devendo os Estados partes tomarem todas as medidas para garantir o acesso daqueles em igualdade de condições aos planos existentes, por exemplo, eximindo-lhes dos requisitos de residência quando corresponda e dispondo possibilidades de receber as prestações ou outros serviços no lugar de deslocamento. Por sua vez, os migrantes internos devem poder ter acesso à seguridade social em seu lugar de residência e os sistemas de registro de residência não devem restringir o acesso à seguridade social das pessoas que se deslocam a outro distrito onde não estejam registrados (ONU, ECOSOC, Doc. E/C.12/GC/19, 2007, par. 39, p. 13).

Já em sua Observação Geral no 23 adotada durante sua 57̣ sessão, realizada entre 22 de fevereiro a 04 de março de 2016, o Comitê interpretou o direito a condições justas e favoráveis do trabalho, conforme dispõe o artigo $7^{\circ}$ do Pacto. Este estabelece o direito a uma remuneração mínima do trabalho, estipulando um salário equitativo suficiente para garantir umas condições de existência dignas, assim como condições de trabalho equitativas e satisfatórias. Os salários devem ser equitativos e adequados para que sejam 
considerados justos. Ademais, as pessoas devem desfrutar de umas condições mínimas de saúde e higiene no ambiente de trabalho, cabendo aos Estados partes a responsabilidade em adotar políticas públicas e leis orientadas para essas finalidades. Estes também devem estabelecer um nível de referência ou mínimo, não permitindo que as condições de trabalho de nenhuma pessoa sejam inferiores às estabelecidas para esse patamar. À luz do artigo $7 \underline{0}$, os Estados partes devem estabelecer medidas coercitivas que garantam a aplicação desses direitos. Nesse artigo o PIDESC desenvolve explicitamente a dimensão individual do direito ao trabalho mediante o reconhecimento do direito de toda pessoa a condições de trabalho equitativas e satisfatórias, especialmente a segurança das condições de trabalho.

O CDESC destacou no apartado "E" dessa Observação Geral os chamados temas especiais de ampla aplicação. Dentre esses, figuram os trabalhadores migrantes particularmente porque quando se encontram não documentados em um determinado país estão expostos, dentre outras situações, à exploração, longas jornadas de trabalho, salários injustos, ambientes de trabalho perigosos e insalubres. Esse conjunto de vulnerabilidades agrava-se por práticas trabalhistas abusivas que conferem ao empregador controle sobre a situação de residência do trabalhador migrante, vinculando-o com um empregador específico. Se não falam o idioma nacional é possível que tenham ainda um menor conhecimento de seus direitos, impossibilitando assim o acesso aos devidos mecanismos de reparação. O Comitê também sublinhou o fato de que os trabalhadores indocumentados quase sempre temem não só represálias por parte dos empregadores, como uma possível expulsão no caso de denúncia de suas condições de trabalho. Portanto, as leis e políticas públicas deveriam velar para que os trabalhadores migrantes gozem de um tratamento não menos favorável àquele dispensado aos trabalhadores nacionais em quanto à remuneração e condições de trabalho (ONU, ECOSOC, Doc. E/C.12/GC/23, 2016, par. 47.e, p. 14).

O CDESC também assinalou preocupação relevante para com os refugiados. Isso porque debido à precariedade de suas situações, continuam vulneráveis à exploração, à discriminação e ao abuso no ambiente de trabalho. Estes podem estar piores remunerados, com jornada de trabalho mais prolongadas e condições de trabalho mais perigosas com relação aos nacionais. Igualmente, à luz do princípio da igualdade e não discriminação, os Estados partes do PIDESC deveriam promulgar leis que permitam aos refugiados condições não menos favoráveis que as dos nacionais (ONU, ECOSOC, Doc. E/C.12/GC/23, 2016, par. 47.i, p. 15).

Em sua Observação Geral no 13, o CDESC tratou o direito à educação conforme o artigo 13 do PIDESC. Para o Comitê a eduacação é um direito humano intrínseco e um meio indispensável para a realização de outros 
direitos. Como direito do âmbito da autonomia da pessoa, a educação é o principal meio que permite a adultos e menores marginalizados econômica e socialmente sair da pobreza e ter participação plena em suas comunidades. A educação desempenha um papel decisivo na emancipação da mulher; na proteção das crianças contra a exploração laboral, o trabalho perigoso e a exploração sexual; na promoção dos direitos humanos e na democracia, na proteção do meio ambiente e no controle demográfico. O CDESC destaca que a educação é um dos melhores investimentos financeiros que os Estados podem fazer, pois possuir uma mente instruída, inteligente e ativa, com liberdade e amplidão de pensamento, é um dos prazeres e recompensas da existência humana. Pontualiza que no contexto das disposições do PIDESC relativas à não discriminação e à igualdade, o direito ao ensino técnico e professional abarca programas destinados a promover o ensino para as mulheres, as crianças, os jovens não escolarizados, os jovens sem emprego, os filhos de trabalhadores migrantes e os refugiados, dentre outros grupos desfavorecidos (ONU, ECOSOC, Doc. E/C.12/1999/10, 1999, par. 16.e, p. 6).

A nona observação, através da qual o CDESC precisa o conteúdo do dever dos Estados em dar efetividade ao PIDESC, também é auspiciosa. O direito a um recurso efetivo não deve ser interpretado sempre e necessariamente no sentido de um recurso judicial. Os recursos administrativos também estão aí contemplados e devem ser acessíveis, não onerosos, rápidos e eficazes, inclusive contando com um último direito de apelação judicial resguardando esses procedimentos. Ademais, no parágrafo 9 desse Comentário, o CDESC clama pela justiciabilidade de todos os direitos contidos no PIDESC e afirma que quando um direito reconhecido no Pacto não possa ser exercido plenamente sem uma intervenção do Poder Judiciário, faz-se-á necessário estabelecer recursos judiciais (ONU, ECOSOC, Doc. E/C.12/1998/24, 1998, par. 9, p. 3-4).

O CDESC é atento para a afirmação da universalidade, indivisibilidade e interdependência dos direitos humanos. Em um mundo marcado pela diversidade e pluralidade, a promoção e o respeito cabal dos direitos culturais são essenciais para a manutenção da dignidade humana e para a positiva interação social de indivíduos e comunidades. Segundo o Comitê, os Estados partes do PIDESC devem estar especialmente atentos para a proteção da identidade cultural dos migrantes, assim como de seus idioma, religião, folclore, direito a organizar eventos culturais, artísticos e interculturais. Ademais, os Estados partes não devem impedir que os migrantes mantenham seus laços culturais com seus países de origem (ONU, ECOSOC, Doc. E/C.12/ GC/21/Rev.1, 2009, par. 34, p. 9).

Levando em consideração o laço de confidencialidade intrínseca entre cultura e educação, o CDESC recomenda aos Estados partes, através de sua observação geral no 21, adotarem medidas adequadas para que os filhos dos 
migrantes possam assistir, em condições de igualdade de trato, às instituições e aos programas públicos de ensino (ONU, ECOSOC, Doc. E/C.12/GC/21/ Rev.1, 2009, par. 35, p. 9).

\section{A migração nas declarações e cartas abertas do CDESC}

Somam-se também ao acervo de produções do Comitê uma série de declarações e de cartas abertas. Estas buscam chamar a atenção dos Estados partes e da comunidade em geral acerca de assuntos conexos com o PIDESC que estão sendo objetos da agenda universal por meio de conferências internacionais, especialmente do sistema $\mathrm{ONU}$; ademais de fenômenos universais civis, culturais, econômicos, políticos ou sociais de especial impacto sobre os DESC. Dentre outras, merece destaque a Carta do Presidente do Comitê sobre Medidas de Austeridade de 16 de maio de 2012, por meio da qual o Comitê recorda aos Estados partes que conforme o Pacto, todos eles devem evitar a adoção de decisões que possam redundar na denegação ou vulneração de direitos econômicos, sociais e culturais, pois estas podem provocar insegurança social e instabilidade política; ter efeitos negativos importantes, em particular sobre as pessoas e os grupos desfavorecidos e marginalizados, como os migrantes e os refugiados. Dadas a indivisibilidade, interdependência e inter-relação dos direitos humanos, nesse processo também se encontram ameaçados outros direitos (CDESC, 2012, par. 3, p. 1).

Pedra angular nos documentos oficiais do Comitê no tocante à temática migratória em sua dimensão mais ampla é a intitulada Declaração do CDESC quanto às Obrigações dos Estados com respeito aos Refugiados e aos Migrantes em virtude do PIDESC. Nesta o CDESC recorda aos Estados partes as garantias estabelecidas para os refugiados e migrantes no Pacto (ONU, ECOSOC, Doc. E/C.12/2017/1, 2017, p. 1-6).

Sua importância já é notada em seus parágrafos inaugurais. O Comitê aclara que os direitos contidos no PIDESC devem ser desfrutados por todas as pessoas que se encontrem na jurisdição de um de seus Estados partes. Isto inclui aos migrantes em geral, aos solicitantes de refúgio e aos refugiados já reconhecidos. Inclusive estando estes em situação irregular. Observa que no caso dos refugiados, o Pacto deve ser considerado complementariamente à Convenção sobre o Estatuto dos Refugiados das Nações Unidas de 1951 e ao seu Protocolo de 1967. Em virtude do PIDESC, o requisito de garantir todos os direitos sem nenhuma discriminação impõe aos Estados partes uma obrigação imediata. Porém, certa margem de apreciação é concedida aos Estados para que adotem medidas objetivando efetivar progressivamente os direitos enunciados no PIDESC, sempre e quando tais medidas sejam deliberadas, concretas e orientadas para a satisfação das obrigações reconhecidas no Pacto (ONU, ECOSOC, Doc. E/C.12/2017/1, 2017, par. 2-3, p. 1-2). 
Apesar dos Estados partes deverem acolher a afluência de refugiados e migrantes em consonância com o alcance do máximo de recursos disponíveis, em princípio não estaria justificada a limitação do exercício do conteúdo essencial dos direitos amparados pelo Pacto mediante argumentação da falta de recursos, ainda quando afrontarem um fluxo repentino e quantativamente importante de refugiados. Isso conforme assinalado pelo próprio CDESC em sua declaração sobre a pobreza de 2001 quando diz que as obrigações essenciais são inderrogáveis e não se extinguem em situações de conflito, emergência ou desastre natural (ONU, ECOSOC, Doc. E/C.12/2017/1, 2017, par. 10, p. 3).

$\mathrm{O}$ acolhimento de pessoas pelos Estados partes do PIDESC deve ser livre de qualquer discriminação por motivos de suas nacionalidades ou condições jurídicas. Trata-se de uma proibição absoluta e imediata que alcança a proteção da dignidade dos migrantes, refugiados já reconhecidos e solicitantes de refúgio nestes Estados. Assim sendo, toda distinção, exclusão, restrição, preferência ou outro tratamento diferente por motivos de nacionalidade ou condição jurídica deve ser ajustado à lei, buscar uma finalidade legítima e ser sempre proporcional ao fim perseguido (ONU, ECOSOC, Doc. E/C.12/2017/1, 2017, par. 5. p. 2).

Como membros das Nações Unidas, os Estados partes do PIDESC se comprometeram, à luz dos artigos 2, parágrafo 1.11, parágrafo $2 \mathrm{~b}$ ), 22 e 23, a cooperar em aras da plena efetivação dos direitos estabelecidos no PIDESC. Para o CDESC, na temática migratória, a assistência e a cooperação internacionais são necessárias para que os Estados enfrentem uma afluência maciça e repentina de refugiados e migrantes (ONU, ECOSOC, Doc. E/C.12/2017/1, 2017, par. 18, p. 5).

\section{A migração nas observações conclusivas do CDESC}

As observações conclusivas são o documento oficial produzido pelo Comitê após o diálogo construtivo e interativo com os Estados partes no PIDESC. Estas contêm um parágrafo de preocupação e outro de recomendação emanados pelo CDESC acerca dos distintos assuntos tratados durante o diálogo. É o ápice da metodologia oficial da apresentação de relatórios pelos Estados partes no Pacto.

As preocupações com os solicitantes de refúgio, refugiados reconhecidos e outros migrantes sempre marcaram esses documentos como consequência do diálogo com os mais diversos Estados partes. Isso significa que o Comitê destila uma atenção especial a esses grupos.

A recomendação referente ao parágrafo 16 das Observações Conclusivas oriundas do 20 Relatório Periódico do Estado brasileiro, aprovada durante a 23a sessão do CDESC realizada em 19 de maio de 2009 merece destaque. Nesta, o Comitê recomendou ao Brasil que continuasse fortalecendo os mecanismos jurídicos e institucionais dirigidos a lutar contra a discriminação no âmbito do 
emprego, facilitando às mulheres e às pessoas pertencentes a minorias raciais, étnicas e nacionais a igualdade de acesso às oportunidades de emprego (ONU, ECOSOC, Doc. E/C.12/BRA/CO/2, 2009, par. 16, p. 5-6).

Em 2015, no âmbito das Observações Conclusivas referentes à apresentação do 2 o Relatório Periódico do Estado grego, o CDESC dedicou um apartado especial aos migrantes, solicitantes de refúgio e refugiados na Grécia. Ao apreciar os esforços do Estado parte para receber e acolher um número excepcionalmente alto de migrantes e pessoas que fogem de conflitos armados e perseguições, assim como sua continuada cooperação com o ACNUR, o Comitê preocupou-se com a insuficiência e as condições precárias dos centros de acolhida destas pessoas. Em consequência, recomendou ao Estado grego empenhar-se para que os migrantes, solicitantes de refúgio e refugiados desfrutassem plenamente de seus direitos econômicos, sociais e culturais. Ademais, recomendou que se buscasse fortalecer a assistência e a cooperação internacionais, particularmente com os países membros da União Europeia. Igualmente, agisse para aumentar o número de centros de acolhida, melhorasse as condições de vida nesses centros e garantisse que as pessoas acolhidas tivessem acesso à assistência médica, intérpretes, suficiência alimentar, roupas e apoio social (ONU, ECOSOC, Doc. E/C.12/GRC/CO/2, 2009, par. 11-12, p. 3).

Nas observações conclusivas relativas ao 5 o Relatório Periódico da Itália, o CDESC valorizou os esforços realizados pelo Estado parte quanto aos migrantes, solicitantes de refúgio e refugiados em recebê-los, acolhê-los em número elevado, exemplificando com o lançamento da operação Mare Nostrum em 2013. Destacou seguir preocupado com a prática do rechaço e restrições ao gozo dos direitos reconhecidos no PIDESC por estes. Finalmente, manifestou preocupação particular quanto ao número insuficiente de centros de acolhimento em território italiano, bem como com suas condições precárias. Consequentemente, instou a Itália terminar com a prática do rechaço e assegurar os direitos econômicos, sociais e culturais dessas pessoas. Por fim, recomendou ao Estado parte tomar todas as medidas necessárias para aumentar o número de centros de acolhimento, melhorar as condições de vida nesses centros e assegurar que todas as pessoas que neles se encontram disponham de atenção médica, intérpretes, comida suficiente, roupa e apoio social (ONU, ECOSOC, Doc. E/C.12/ITA/CO/5, 2015, par. 18-19, p. 3-4).

Dos retromencionados exemplos grego e italiano emerge uma prática consolidada do CDESC na elaboração de suas preocupações e recomendações aos Estados em matéria de migrantes, refugiados e solicitantes de refúgio, especialmente no que toca à prática do rechaço da acolhida, à quantidade de centros de acolhimento e condições de integração na esfera de saúde, comunicação e alimentação dessas pessoas. 
Em suas observações conclusivas, o CDESC se debruça sobre a discriminação dirigida a nacionalidades específicas no território de seus Estados partes. Tal é o caso da discriminação contra pessoas de origem haitiana na República Dominicana. Nas observações conclusivas relativas ao 4o Relatório Periódico apresentado por este Estado, o Comitê, ao lamentar que a República Dominicana não houvesse dado cumprimento à sua recomendação anterior, ressaltou sua preocupação continuada pela persistente discriminação que enfrentam as pessoas haitianas, bem como seus ascendentes em território dominicano. Ao lamentar a sentença TC/0168/13 do Tribunal Constitucional, que privou a nacionalidade de maneira retroativa às pessoas de ascendência haitiana, que haviam nascido e vivido durante décadas em território dominicano, o Comitê instou ao Estado parte adotar todas as medidas legislativas e administrativas necessárias para combater todas as formas de discriminação que causam ou perpetuam a discriminação formal ou de fato contra os haitianos e os dominicanos de ascendência haitiana. Ademais, que adotasse todas as medidas necessárias para evitar que a sentença TC/0168/13 continuasse produzindo efeitos jurídicos. E, finalmente, que a República Dominicana garantisse o reestabelecimento da nacionalidade a todas as pessoas afetadas por tal sentença, inclusive eliminando trâmites e requisitos excessivos para a recuperação de suas nacionalidades (ONU, ECOSOC, Doc. E/C.12/DOM/CO/4, 2016, par. 21-22, p. 4-5).

O CDESC preocupa-se pelo impacto negativo de legislações abusivas sobre os migrantes, refugiados e solicitantes de refúgio. Prova disso é o parágrafo 26 das observações conclusivas relativas ao 6을 Relatório Periódico da Alemanha. Por seu intermédio, o Comitê preocupou-se que o artigo 87, parágrafo 2, da Lei de Residência germânica obrigasse as autoridades públicas a denunciar os migrantes indocumentados às autoridades de imigração, o que poderia dissuadir os trabalhadores migrantes em situação irregular a solicitar serviços, como atenção à saúde e denunciar delitos, incluídos a violência doméstica, a violência sexual e de gênero. Como recomendação, solicitou ao Estado parte que estabelecera uma clara separação entre os provedores de serviços públicos e as autoridades de imigração (ONU, ECOSOC, Doc. E/C.12/DEU/CO/6, 2018, par. 26-27, p. 5).

Nessa mesma observação conclusiva o CDESC mostrou-se preocupado com a fragilização do princípio da reunião familiar dos refugiados e das pessoas sob proteção subsidiária na Alemanha. Eis que o Comitê observou que tal princípio, possível desde 2015 e restabelecido trás estar suspenso entre março e julho de 2018, vigorava com uma cota de 1000 pessoas mensais, ainda que subsistissem exceções por razões humanitárias. Essa nova regulamentação não estava clara quanto aos seus procedimentos e critérios de aplicação. Em consequência, o Comitê recomendou a aplicação cabal do princípio da reunião 
familiar e que o Estado parte reduzisse os obstáculos práticos e administrativos para a afirmação de tal princípio angular no direito internacional dos refugiados (ONU, ECOSOC, Doc. E/C.12/DEU/CO/6, 2018, par. 28-29, p. 5).

Os solicitantes de refúgio também são públicos de atenção especial por parte do CDESC. Nas observações conclusivas relativas ao Relatório Inicial da África do Sul, o Comitê aplaudiu o acolhimento pelo Estado parte de um número elevado de refugiados e solicitantes de refúgio. No entanto, preocupou-lhe a denegação a estes últimos do direito a trabalhar e a demora na tramitação e decisões das solicitações de refúgio, o que poderia restringir o acesso dos solicitantes de refúgio à assistência jurídica, à atenção médica, à educação e às prestações sociais. Ato contínuo, o CDESC recomendou ao estado sul-africano tramitar sem demora as solicitações de refúgio pendentes, garantindo aos solicitantes o direito ao trabalho e o acesso aos serviços sociais como saúde, educação e assistência social (ONU, ECOSOC, Doc. E/C.12/ ZAF/CO/1, 2018, par. 25-26, p. 5).

O CDESC observa com preocupação o grande número de deslocados internos em razão da violência generalizada e das crises de segurança em diferentes regiões do planeta. Em sua Observação Conclusiva sobre o 4 o Relatório Periódico de Camarões, o Comitê exortou o Estado parte a evitar tomar ações capazes de provocar deslocamentos forçados de sua população e adotar medidas apropriadas e razoáveis para prevenir esses deslocamentos internos. Assim mesmo, recomendou ao estado camaronês que proporcionasse proteção efetiva aos deslocados internos, aos refugiados e aos solicitantes de refúgio. Finalmente, recomendou a Camarões velar para que os deslocados internos regressassem para suas regiões de origens em plena segurança e dignidade ou thes proporcionasse soluções alternativas adequadas (ONU, ECOSOC, Doc. E/C.12/CMR/CO/4, 2019, par. 8-9, p. 3).

\section{O Protocolo Facultativo ao PIDESC}

O Protocolo Facultativo ao PIDESC é um tratado internacional unanimemente adotado pela Assembleia Geral da ONU em 10/12/2008 (Resolução A/RES/63/117). Em 2009, ele foi aberto para a assinatura dos Estados partes no PIDESC e, em 05 de fevereiro de 2013, alcançou seu décimo depósito. Este possibilita ao CDESC considerar comunicações individuais envolvendo assuntos relacionados aos direitos humanos no contexto do PIDESC. Dentre estas, as relativas a pretensas violações de direitos dos migrantes, refugiados e solicitantes de refúgio que se encontram na jurisdição de um dos Estados parte do PIDESC e de seu protocolo.

O quarto artigo do regulamento do Protocolo diz que as comunicações poderão ser apresentadas por pessoas ou grupos de pessoas que se encontrem sob a jurisdição de um Estado parte e que aleguem serem vítimas de uma 
violação de qualquer dos direitos enunciados no PIDESC. Esse fato confere um posicionamento especial ao CDESC com relação aos demais órgãos internacionais não judiciais e, também, judiciais de proteção dos direitos econômicos, sociais e culturais. A possibilidade da cidadania dos Estados partes no protocolo facultativo ao PIDESC denunciar individualmente seus países alça o CDESC como o único órgão internacional, na atualidade, capacitado para receber denúncias individuais referentes à violação dos DESC contidos no Pacto.

O sétimo artigo do regulamento consagra na seara dos DESC uma importante ferramenta contemporânea de proteção internacional dos direitos humanos: as medidas provisórias de proteção. Uma vez recebido a denúncia de violação de um dos artigos do PIDESC por um de seus Estados partes, o Comitê poderá, em circunstâncias excepcionais e antes de tomar uma decisão sobre o mérito do caso, transmitir a esse Estado, para seu exame urgente, uma petição no sentido de que se adotem as medidas provisórias para evitar um possível dano irreparável à vítima da violação denunciada. Tudo isso, sem prejulgar a decisão a ser tomada sobre a admissibilidade ou o mérito da petição.

Até o momento, não houve nenhum caso envolvendo migrantes, refugiados ou solicitantes de refúgio. Mas essa janela de proteção também está aberta para estes públicos e todo aquele que se encontra na jurisdição de um Estado parte do PIDESC e de seu protocolo.

\section{Conclusão}

A existência de um verdadeiro regime de proteção aos migrantes, refugiados e solicitantes de refúgio emergida do PIDESC é irrefutável. Nota-se um conjunto de normas sólidas (o PIDESC e seu protocolo), instituições (ONU, CDESC e Estados partes), princípios reconhecidos (Igualdade e Não Discriminação, Pro Homine e União Familiar), documentos oficialmente reconhecidos pelos Estados partes (observações conclusivas, observações gerais, cartas e declarações), capazes de gerar um padrão de conduta nos Estados partes do PIDESC e contribuir à afirmação da dignidade humana das pessoas sob suas jurisdições.

Os desafios a esse regime são as provocações enfrentadas pelo próprio multilateralismo. Como se trata de um regime universal de proteção, que nasce e emerge no seio das Nações Unidas, dever-se-á velar por sua sustentabilidade financeira; a independência e imparcialidade dos 18 membros que compõe o CDESC; a participação ativa da sociedade civil organizada em todas as etapas do diálogo construtivo com os Estados, senão ainda na elaboração das distintas produções do Comitê; trabalhar para que mais Estados partes do PIDESC ratifiquem o seu Protocolo Facultativo; e potencializar a sinergia com todos os 
demais atores do sistema de órgãos de tratados de direitos humanos da ONU. Estes são pontos cruciais para garantir a vitalidade institucional, normativa e principiológica desse regime. Essas tarefas competem fundamentalmente aos Estados partes do PIDESC, avalistas e guardiães principais desse regime. Não obstante, estes devem ter a confidência e o esforço conjunto de todos os atores do sistema ONU e da sociedade civil organizada. Finalmente, na seara da afirmação da dignidade humana e da proteção internacional da pessoa humana, a sorte de cada um está inexoravelmente conectada à dos demais.

Destaca-se, porém, caber primordialmente aos Estados partes do PIDESC a responsabilidade em adotar políticas públicas, medidas administrativas e leis orientadas para o gozo efetivo dos direitos e deveres contidos no PIDESC. Foram eles quem assumiram de boa-fé esse compromisso perante a comunidade internacional.

\section{Referências bibliográficas}

ACNUR. Tendência Globais. Genebra: ACNUR, 2019.

CDESC. Observação Geral no 3. In: ONU. Instrumentos Internacionales de Derechos Humanos. Documento HRI/GEN/1/Rev.9 (v. I), 27 de maio de 2008.

CDESC. Carta de fecha 16 de mayo de 2012 dirigida a los Estados partes en el Pacto Internacional de Derechos Económicos, Sociales y Culturales por el Presidente del Comité de Derechos Económicos, Sociales y Culturales. 2012.

KRASNER, Stephen D. Structural Causes and Regime Consequences: Regime as Intervening Variables. International Organization, v. 36, n. 2, p. 185-205, Spring 1982.

LEÃO, Renato Zerbini Ribeiro. O reconhecimento do refugiado no Brasil no início do Século XXI. In: BARRETO, Luiz Paulo Teles Ferreira (org.). Refúgio no Brasil: a proteção brasileira aos refugiados e seu impacto nas Américas. Brasília: ACNUR, CONARE, MJ, 2010, p. 71-96.

ONU. Comitê de Direitos Humanos, Observação Geral no 18: Não Discriminação, CCPR/C/37, de 10 de noviembre de 1989.

ONU. Comité de Derechos Económicos, Sociales y Culturales. Folleto Informativo, n. 16 (Rev. 1). Campaña Mundial pro Derechos Humanos. OACNUDH: Genebra, 1996.

ONU. Los Derechos Económicos, Sociales y Culturales - Manual para las Instituciones Nacionales de Derechos Humanos. Serie de Capacitación Profesional no 12 Derechos Humanos. ACNUDH: Ginebra, 2004.

ONU. Instrumentos Internacionales de Derechos Humanos. Documento HRI/GEN/1/ Rev.9 (v .I), de 27 de maio de 2008.

ONU. ECOSOC. Documento E/C.12/1998/24. Observación general num. 9 sobre la aplicación interna del PIDESC. 03/12/1998.

ONU. ECOSOC. Documento E/C.12/1999/10. Observación general num. 13 (1999) sobre el derecho a la educación (artículo 13 del Pacto Internacional de Derechos Económicos, Sociais y Culturales). 08/12/1999. 
ONU. ECOSOC. Documento E/C.12/2000/4. Observación general num. 14 (2000) sobre el derecho al disfrute del más alto nível posible de salud (artículo 12 del Pacto Internacional de Derechos Económicos, Sociais y Culturales). 11/05/2000.

ONU. ECOSOC. Documento E/C.12/GC/18. Observación general num. 18 (2006) sobre el derecho al trabajo (artículo 6 del Pacto Internacional de Derechos Económicos, Sociais y Culturales). 24/11/2005.

ONU. ECOSOC. Documento E/C.12/GC/19. Observación general num. 19 (2007) sobre el derecho a la seguridad social (artículo 9 del Pacto Internacional de Derechos Económicos, Sociais y Culturales). 23/11/2007.

ONU. ECOSOC. Documento E/C.12/GC/20. Observación general num. 20 (2009) La no discriminación y los derechos económicos, sociales y culturales (artículo 2, párrafo 2 del Pacto Internacional de Derechos Económicos, Sociales y Culturales). 23/11/2009.

ONU. ECOSOC. Documento E/C.12/GC/21/Rev.1. Observación general num. 21 (2009) sobre el derecho de toda persona a participar em la vida cultural (artículo 15, párrafo 1 a), del Pacto Internacional de Derechos Económicos, Sociais y Culturales). 19/11/2009.

ONU. ECOSOC. Documento E/C.12/GC/23. Observación general num. 23 (2016) sobre el derecho a condiciones de trabajo equitativas y satisfactorias (artículo 7 del Pacto Internacional de Derechos Económicos, Sociais y Culturales). 27/04/2016.

ONU. ECOSOC. Documento E/C.12/2017/1. Obligaciones de los Estados com respecto a los refugiados y los migrantes em virtud del Pacto Internacional de Derechos Económicos, Sociais y Culturales. Declaración del Comité de Derechos Económicos, Sociales y Culturales. 13/03/2017.

ONU. ECOSOC. Documento E/C.12/BRA/CO/2, Oservações Conclusivas do $2 \underline{0}$ Relatório Periódico de Brasil. Sessões $6^{\underline{a}}$, 7aㅡ e $8^{\underline{a}}$ do CDESC realizadas nos dias 6 e $7 / 5 / 2009$.

ONU. ECOSOC. Documento E/C.12/GRC/CO/2, Oservações Conclusivas do 2o Relatório Periódico da Grécia. Sessões 70aㅡ e 71ํㅡ do CDESC realizadas nos dias 5 e 6/10/2015.

ONU. ECOSOC. Documento E/C.12/ITA/CO/5, Oservações Conclusivas do 5으 Relatório Periódico da Itália. Sessões $57^{a} \underline{a}$ e $58^{\underline{a}}$ do CDESC realizada no dia 25/9/2015.

ONU. ECOSOC. Documento E/C.12/DOM/CO/4, Oservações Conclusivas do 4은 Relatório Periódico da República Dominicana. Sessões 63aㅡ e 64aㅗ do CDESC realizadas nos dias 27 e 28/9/2016.

ONU. ECOSOC. Documento E/C.12/DEU/CO/6, Oservações Conclusivas do 6을 Relatório Periódico da Alemanha. Sessão 58 a do CDESC realizada no dia 25/9/2018.

ONU. ECOSOC. Documento E/C.12/ZAF/CO/1, Oservações Conclusivas do Relatório Inicial da África do Sul. Sessão 58a ${ }^{a}$ do CDESC realizada no dia 12/10/2018.

ONU. ECOSOC. Documento E/C.12/CMR/CO/4, Oservações Conclusivas do 4으 Relatório Periódico de Camarões. Sessão 60ª do CDESC realizada no dia 8/3/2019. 